\title{
Innovation Research of Automobile Marketing Mode in "Internet+" Age
}

\author{
Jun-Tao XIAO', a , Yu LIU ${ }^{2, b}$ and Xiu-Li WANG ${ }^{3, c}$ \\ ${ }^{1}$ Hubei University of Automotive Technology, Shiyan,Hubei, China \\ ${ }^{2}$ Hubei University of Automotive Technology, Shiyan,Hubei, China \\ ${ }^{3}$ Hubei University of Automotive Technology, Shiyan,Hubei, China \\ axiaojuntao00957@163.com, b916129969@qq.com, ${ }^{\mathrm{c}} 734793279 @ q q . c o m$
}

\begin{abstract}
Keywords: "Internet+" interactive automobile marketing mode. Comprehensive electronic business platform. Innovation. Research.

Abstract. With the development of the internet, the traditional automobile marketing mode evolves into the "Internet+" interactive automobile marketing mode. This paper analyzes the connotation, concept, model, advantages and application of the new marketing mode in this new era, and concludes that the implementation of the marketing mode can improve the efficiency and accuracy of the automobile marketing.
\end{abstract}

\section{Introduction}

Automobile marketing mode is composed of marketing organization, marketing tools and marketing concept. The three aspects interact and influence each other. With the era of the internet and mobile internet is coming, the traditional automobile marketing mode is faced with unprecedented challenges. Therefore, the innovation of automobile marketing mode is necessary. "Internet $+"$ interactive automobile marketing mode is put forward on the background.

\section{The traditional automobile marketing mode is facing new problems under "Internet+"}

Traditional automobile marketing mode is mainly composed of $4 \mathrm{~S}$ shop, auto trading market, car supermarkets, etc. Internet technology has been changing the contact between people and the outside world since it came into being. Mobile Internet has made this change more quickly and now even affected the industry. As a result, the traditional automobile marketing mode exist the following problems. First, the management of customer information falls behind. Many companies can't effectively obtain customer information using the Internet, even if gain, the information is often be idle, can not fully used. The second is the marketing cost is high. For expanding new markets, whether automobile dealers or store need to increase investment to the channel members, it will increase the marketing cost. The third is the logistics channel is not unobstructed. In the traditional marketing model, because the channel link is numerous and the cycle of delivery and feedback is long, it is easy to cause the interruption of the logistics link and product unmarketable. The fourth is the channel management is more difficult. With the expansion of the power and scale, the car dealers will probably appear to the phenomenon: it requires more input and rebate from the upstream automobile manufacturing enterprise and require improve the purchase price from downstream auto retailers, so the channel management is harder. Five is the market competition is disorderly. Automobile dealers are mainly distributed in the developed regions and cities, the automotive product's price is different with different regions and even at the same area the competition between dealers is vicious, which caused the market disorder. Six is the model of integrated automotive electrical business has not yet formed. Although many automobile enterprises and dealers have established their own e-commerce platform, the difficulty of information processing is increased when consumers buy a car because of the lack of integrated function.

To solve problems above, a new perspective is put forward for the automotive industry by the "Internet +", new requirements are put forward for automobile marketing mode, too. One is to change marketing concept. Not centered on "product" but with "customers as the center", take the customer demand and experience as the center, and the needs of customers can be timely learned by enterprise 
through the Internet and mobile Internet and implemented in the design, production and sales. Two is optimizing marketing organization. Auto parts suppliers, auto manufacturing enterprises, sales enterprises should break the barrier of the industry, realize sharing of information resources and make them real-time link with customers by "intelligent", so the coordinated development can be realized. Three is to improve the marketing tools. The development of the Internet and mobile Internet lead to big data, cloud computing and the use of 3D printing technology, the use of these new technologies and methods will lead to the improvement of marketing tools and high efficiency of marketing.

\section{"Internet + " interactive automobile marketing mode}

"Internet + " interactive automobile marketing mode is based on a comprehensive electric business platform, the automobile production enterprise, dealers, consumers and other related group achieve real-time links, multidimensional interaction, breaking the barrier of the industry, integration of online to offline through the internet port and ultimately realize the marketing mode of precision, intelligent and humanization. The design concept of the marketing model is as follows. On the marketing concept, make customer demand as the guidance, innovation as the driving force, give full consideration to factors such as resource, traffic, environment, combining with the new thinking of "Internet +", break the barriers between traditional value chain, realize sharing of information resources. On the marketing organization, an independent comprehensive auto mall electric business platform is to be built on the base of $4 \mathrm{~S}$ shop, auto trading market, etc. The electric business platform is the integration of the existing automobile enterprise resources and has a variety of functions. On the marketing tools, the business closed loop of information flow, commodity flow, cash flow is formed through the comprehensive electric business platform, the information of goods and services is achieved by using PC, mobile phone end and car networking, the real, scientific and effective customer information is got by making use of big data and cloud computing. The operation mechanism of "internet + " interactive automobile marketing mode is as follow.

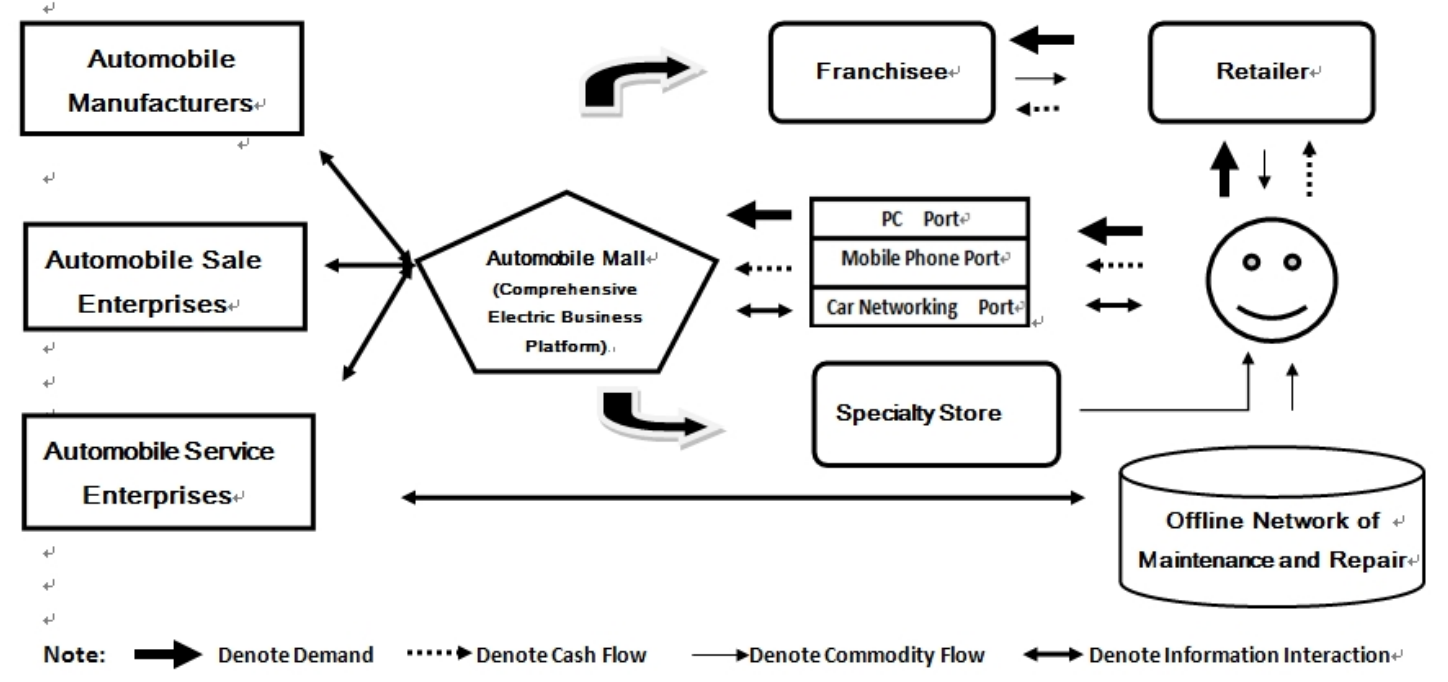

Comprehensive electronic business platform has following functions. One is provide comprehensive service for customer purchasing cars. Usually, consumer need to experience four stages buying car, that is the process of information collection, information comparison, firsthand experience and eventually buy .In the four stages, consumers can be provided comprehensive services using comprehensive automobile e-commerce platform. Consumers can enter into the comprehensive electric business platform anytime and anywhere through the PC, mobile phone and car networking etc, in which consumers can obtain all information about the product, even can obtain other similar product information according to the comparison and big data analysis. The comprehensive electric business platform will provide purchase instructions according to the relevant information after consumers determine buying some king of product.. Consumers can also obtain more automotive product information interact with the corresponding car sales enterprise through the platform, and of 
course ask for test drive. Consumers can offer and submit the order through the electric business platform upon completion of test drive. The order is directly received by the dealers from the platform and the dealers send the car to consumer. Two is to provide comprehensive service for customer maintaining and repairing cars. In car maintenance service, comprehensive automobile e-commerce platform can accurately provide each owner a maintenance plan by processing the vehicle information from the car network. Customers can also make an appointment to the maintenance center through this platform. The platform informs customers the best maintenance center through the study of the positioning and requirement of the customer. When the automobile needs repair, customers can send information to the platform through the mobile phone or car network port. The platform not only will immediately inform the nearest vehicle repair center to rescue but also point out the malfunction according to the information of the terminal monitoring. Tree is to provide Interactive platform between automobile designers, producers, sellers, buyers and users. Customers can interact with auto enterprise to propose ideas and suggestions for the product design, performance, quality, price and service through the comprehensive automotive electronic commerce platform. The automobile enterprises will analysis and summary the information provided by the users, and used to improve products and services. The automobile enterprises even can produce personalized automobile according to the requirements of customers.

\section{What is the advantage of "Internet + " interactive automobile marketing mode?}

The "internet + " interactive automobile marketing mode has the following advantages compared with the traditional marketing model. One is the way of quotation is more fast. The quotation between automobile products producers and dealers, auto dealers and retailers, car buyers and retailers is completed by comprehensive electric business platform. Consumers can choose to buy automotive products or services through effectively comparing with enterprise and enterprise, product and products, services and services on the electric business platform. This approach has the more incomparable swifter than traditional automobile marketing mode. Two is the method of payment is more secure. The payment method of "third-party guarantee" is introduced on the "internet + " interactive marketing model, the comprehensive electric business platform play the role of the third party guarantee at the same time. The consumers will firstly amount to pay to the electric business platform when they are buying the car products, and then the electric business platform will pay to the corresponding car companies after the automobile production is received by consumers. Three is the way of promotion is more accurate. The customer information is completely collected through the comprehensive electric business platform, and the potential demand of consumers is successful predicted by using of big data and cloud computing technology. So the accurate marketing is carried out at the right time, right place, right channel, or customer's consumption potential is inspired through various forms of sales promotion. Five is the technical service and support is more comprehensive. In terms of automobile enterprises, the technical service and support is very important, it is one of the important embodiment of the core competitiveness of enterprises with the product function is increasingly convergence now. The "internet + " interactive marketing model at least provide three aspects of technical service and support for customers, that is all Internet access to information, real-time interactive link, maintain accurate rescue.

\section{How to apply the advantage of "Internet +" interactive automobile marketing mode?}

The following respects should be noted when the "Internet + " interactive marketing mode is used. First is the system of comprehensive electric business platform has proactive and complementary. "Internet + " interactive marketing model is a new model under the background of "Internet + " and is based on the basis of full use of modern information technology. The system of the mode must have the function of the sustainable improvement with the development of the modern information technology. It should not only meet the needs of now, but also should consider the development and changes in the future. The second is needed to redefine the rights and responsibility of relevant market main body. Great changes will take place when the comprehensive electric business platform 
is operating, accordingly the rights and responsibilities of marketing body such as products manufacturers, auto dealers, retailers, customers, etc should be defined and classified again. The third is the service function of comprehensive electric business platform should be given full play to. The comprehensive electric business platform has multiple functions such as multidimensional interaction, data analysis, product trade, product service, product guarantees. These functions play the better, the effect of " Internet +" interactive marketing model is the better. The fourth is to expand the user scale as much as possible and build user ecosystem. Because " Internet + interactive marketing mode is relying on the independent integrated automotive electronic commercial platform, therefore, the more customers used the platform, the better. When the minimum user use quantity is achieved the information resources of related enterprise will be integrated, and then attract more users to join, so cycle, building user ecosystem, finally the "Internet + " interactive marketing mode is be realized completely.

\section{Conclusions}

In this paper, the author creatively put forward the "Internet + " interactive automobile marketing mode under the background of "Internet + ", illustrates the connotation and concept of this model, constructs the operating model, analyses the advantage of the model, and put forward several problems that should pay attention to this pattern. The new mode will greatly improve the precision and efficiency of automobile marketing. Of course, there are many shortcomings on the model, it is very necessary to continuously perfect in practice.

\section{Acknowledgements}

This work was financially supported by the Hubei Social Science Project (15Q129) and Hubei Undergraduate Innovative Entrepreneurial Training Project (201510525007).

\section{References}

[1] Xiao Juntao. Revelation Industrial 4.0 to Our Country Automobile Industry Transformation and Upgrading under New Normal. Journal of Hubei University of Automotive Technological. Vol.2(2015), p. 64-70.

[2] Dong Yang. China's Automobile Industry Challenges and Strategy under New Normal. Journal of Auto Technicians.Vol.5(2015), p.15-17.

[3] Luo Mang and Li Liangyu. The Business Model Innovation in Age of Internet: Based on The Perspective of Value Creation. Journal of Chinese Industrial Economy.Vol.1(2015), p.95-107.

[4] Chen Weiru and Yu Zuoyan,in:Platform Strategy: Revolution of Business Models is Sweeping through the Global,edtied by Citic Publising, China, Beijing(2013),in press.

[5] Li Yining and Zhou qiren,in:The change and decision making under the new normal, edited by

Citic Publishing, China, Beijing(2015), in press. 